\title{
Oculomotor Nucleus
}

National Cancer Institute

\section{Source}

National Cancer Institute. Oculomotor Nucleus. NCI Thesaurus. Code C12897.

A collection of neurons of cranial nerve III located in the rostral half of the midbrain at the level of the superior colliculus, which contain somatic efferent motor neurons that innervate all the extraocular muscles except the superior oblique and lateral rectus. 